\title{
A scoping review on incentives for adoption of sustainable agricultural practices and their outcomes
}

\author{
Valeria Piñeiro ${ }^{1 凶}$, Joaquín Arias $\mathbb{1}^{2}$, Jochen Dürr ${ }^{3}$, Pablo Elverdin ${ }^{4}{ }^{4}$, Ana María lbáñez ${ }^{5}$, \\ Alison Kinengyere $\mathbb{C}^{6}{ }^{6}$, Cristian Morales Opazo ${ }^{7}$, Nkechi Owoo ${ }^{8}$, Jessica R. Page ${ }^{(1}{ }^{9}$, Steven D. Prager $(\mathbb{D} 10$ \\ and Maximo Torero ${ }^{7}$
}

\begin{abstract}
The increasing pressure on agricultural production systems to achieve global food security and prevent environmental degradation necessitates a transition towards more sustainable practices. The purpose of this scoping review is to understand how the incentives offered to farmers motivate the adoption of sustainable agricultural practices and, ultimately, how and whether they result in measurable outcomes. To this end, this scoping review examines the evidence of nearly 18,000 papers on whether incentive-based programmes lead to the adoption of sustainable practices and their effect on environmental, economic and productivity outcomes. We find that independent of the incentive type, programmes linked to short-term economic benefit have a higher adoption rate than those aimed solely at providing an ecological service. In the long run, one of the strongest motivations for farmers to adopt sustainable practices is perceived benefits for either their farms, the environment or both. Beyond this, the importance of technical assistance and extension services in promoting sustainable practices emerges strongly from this scoping review. Finally, we find that policy instruments are more effective if their design considers the characteristics of the target population, and the associated trade-offs between economic, environmental and social outcomes.
\end{abstract}

T he pressure on agricultural production systems to achieve global food security, in the context of growing demands and the degradation of natural resources, makes it necessary to rethink current production systems towards more sustainable models.

In agriculture, environmental sustainability means good stewardship of the natural systems and resources that farms rely on. Among other things, this involves rotating crops and embracing diversity, planting cover crops, no-till systems (or reduced till), integrated pest management, integration between livestock and crops, agroforestry practices and precision farming. The general aim of sustainable agricultural policies is that they ensure environmental sustainability while enhancing, or at least maintaining, farm productivity.

At present, competing uses for land and water resources contribute to the degradation of natural resource capital, a situation that may exacerbate present-day and intergenerational consequences for farmers, other users and the wider population. Sustainable agricultural practices protect the ecosystem through the more efficient use of natural resources and strengthened capacity for adaptation to climate change and climate variability ${ }^{1}$. Therefore, their adoption may have significant benefits for the environment. Moreover, the adoption of sustainable practices is likely to help achieve more resilient and productive food systems and enable sustainable production, which would serve to reduce poverty and advance food security ${ }^{2,3}$. Sustainable agriculture therefore has the potential to directly contribute to several of the United Nations Sustainable Development Goals (SDGs) for 2030, including those relating to poverty (SDG 1), hunger (SDG 2), decent work and economic growth (SDG 8), reducing inequalities (SDG 9), responsible consumption and production (SDG 12), climate action (SDG 13), life below water (SDG 14) and life on land (SDG 15).

The adoption of these sustainable practices usually requires concrete incentives, significant effort from farmers and the support of governments and public-private partnerships at national and local levels. However, the decision to adopt sustainable agricultural practices in response to incentive programmes is not a binary process. Adoption depends on many factors: the conditions of the programme and the incentives offered, as well as the farmers' environmental preferences, economics and cultural characteristics ${ }^{4,5}$. Agricultural market trends also affect producers' decisions ${ }^{6}$.

This scoping review is thus motivated by the need to systematically evaluate the evidence base 6 the effects of incentives offered to farmers to adopt sustainable agricultural practices. To this end, this scoping review examines nearly 18,000 papers on the various incentives that are offered to farmers by governments, non-governmental organizations, international organizations, development banks and other market actors such as consumers and enterprises.

Three kinds of incentives (market and non-market, regulations and cross-compliance, Box 1), as well as their compulsory or voluntary nature, are assessed to determine whether the type of the incentive affects farmers' willingness to adopt. This scoping review also examines the relationship between farmer's adoption of sustainable practices and three types of outcomes: environmental,

IInternational Food Policy Research Institute (IFPRI), Washington DC, USA. ${ }^{2}$ Inter-American Institute for Cooperation on Agriculture (IICA), Panama City, Panama. ${ }^{3}$ Center for Development Research (ZEF), Bonn, Germany. ${ }^{4}$ Group of Producing Countries from the Southern Cone (GPS), Buenos Aires, Argentina. ${ }^{5}$ nter-American Development Bank (IADB), Washington DC, USA. ${ }^{6}$ Makerere University, Kampala, Uganda. ${ }^{7}$ Food and Agriculture Organization (FAO), Rome, Italy. ${ }^{8}$ University of Ghana, Accra, Ghana. ${ }^{9}$ Ohio State University (OSU), Columbus, OH, USA. ${ }^{10}$ International Center for Tropical Agriculture (CIAT), Cali, Colombia. ${ }^{凶}$ e-mail: v.pineiro@cgiar.org 


\section{Box 1 | Incentives, definitions and categories}

Incentives are instruments used by the public and private sectors to encourage farmers to protect or enhance ecosystem services beneficial to them and others (for example, water quality, soil care, forestry), while simultaneously improving the productivity (yields, labour per hectare and so on) and the competitiveness (such as cost per hectare, profitability, farm incomes) of the agricultural sector. These were classified into three categories.

Market-based incentives encourage behavioural change by providing economic incentives through market signals. Examples of these include prices of input and output, subsidy, compensation, income transfer and other incentives in cash or in kind to agricultural producers. Non-market incentives are a broad basket. The parties of the Paris Agreement expressed that a non-market-based mechanism can be anything, provided it is not market-based ${ }^{51}$. This includes technical support, technology transfer and fiscal measures, such as putting a price on carbon or applying taxes to improve environmental sustainability.

Regulatory measures are general rules or specific actions imposed by government agencies or private entities to enhance environmental and economic outcomes through improved practices. Examples include certifications and environmental laws and standards. In general, they are mandatory.

Cross-compliance incentives link direct payments to farmers' compliance with basic standards concerning the environment. They also require farmers to maintain land in good agricultural and environmental condition. In this case, they are mostly voluntary. Examples of these include government subsidies that are conditional on farmers adhering to certain environmental practices.

productivity and economic. Finally, the scoping review draws conclusions on the effectiveness of incentives and the adoption of sustainable farming practices to achieve the desired outcomes. These incentive-adoption-outcome pillars, and the links between them, offer a consistent logic by which to evaluate best practices in sustainable agricultural policy.

This scoping review also considers the broader demographic, social, environmental and economic factors that may drive the observed linkages between incentive, adoption and outcome.

This scoping review finds that regardless of the incentive type, linking programmes to economic benefits (productivity or profitability) is essential for farmers to adopt sustainable agriculture practices in the short term ${ }^{6,7}$. In the long term, one of the strongest motivations for farmers to adopt and maintain sustainable practices is perceived positive outcomes of adoption for their farm or the environment ${ }^{8-11}$. Beyond this, there are important analysis gaps in the existing literature, particularly regarding the interrelationships between the selected incentives, the adoption of best agricultural practices and outcomes. Some suggestions on the next lines of research are included in the analysis.

\section{Results}

The purpose of this scoping review is to understand how incentives motivate the adoption of sustainable agricultural practices and, ultimately, how and whether they result in measurable outcomes. This scoping review looked at the overall landscape of evidence of these instruments and their effectiveness in achieving the key outcomes. As in any scoping review, article screening against the inclusion and exclusion criteria took place in three phases: title screening, abstract screening and full-text screening (Box 2).

This resulted in 577 articles that were evaluated for relevance in terms of connecting either incentives to adoption, adoption to

\section{Box 2 | Abridged methods}

A double-blind title and abstract screening was performed on 17,936 articles using the following inclusion and exclusion criteria:

1. Studies published in 1994 or later.

2. Studies with an explicit focus on incentives for sustainable environmental agricultural practices.

3. Studies with an explicit focus on adoption of sustainable environmental agricultural practices.

4. Studies that explicitly connect the adoption of agricultural practices to sustainability outcomes.

5. Studies with an explicit analysis of the impact of incentives on income, production, productivity, profits and/or environmental sustainability.

6. Original research (qualitative and quantitative reports) and/ or review of existing research including grey literature.

The resulting 1,792 articles were subjected to a second round of rapid review by abstract. This resulted in 577 articles that met the a priori inclusion criteria. A stratified random sample of 99 of these articles were selected for the next step,: full-text screening.

We performed data extraction on 93 of the studies (6 excluded for issues of availability or language). A data extraction template (available in the Supplementary Information) was developed to document the data, study type and context of each citation and all themes of interest.

\section{Why is this method so important?}

Unlike a typical narrative review, a scoping review strives to capture all of the literature on a given topic and reduce authorial bias. Scoping reviews offer a unique opportunity to explore the evidence in agricultural fields to address questions relating to what is known about a topic; what can be synthesized from existing studies to develop policy or practice recommendations; and what aspects of a topic are yet to be addressed by researchers.

measurable outcomes or both sets of links. A machine learning-based approach helped to identify and cluster common terms and topics covered by the three incentive types (Fig. 1). Programmes fell into three broad categories related to ecosystem and environmental interventions, socioeconomic interventions and technological solutions. Articles typically showcased multiple interventions, with $36 \%$ of the total programmes falling under the technical category, and $32 \%$ each falling under the ecosystem and socioeconomic categories.

To better understand the links between incentive, adoption and outcome, a stratified random sample of 99 citations were selected from the 577 articles for additional review and data extraction. Of these, six articles were excluded as they were published in a language not spoken by any of the authors of this research or because full-text versions could not be located.

The subset of 93 articles facilitated more in-depth review of the incentive types. Each article contained a link between either incentives and adoption or adoption and outcomes, or both. For each article, the incentive types were identified, farmers' adoption behaviours as described in the articles were recorded and the corresponding outcomes were noted as a function of the incentives. We found that market and non-market incentives tend to be the most prevalent mechanism (Fig. 2), whereas all three incentive categories are used more or less uniformly to achieve environmental outcomes. Furthermore, profitability-related outcomes tend to require balanced incentive structures, whereas productivity-related outcomes tend to be more market and non-market-oriented (Fig. 2).

Given the importance of understanding when and how incentives drive farmers' adoption behaviours and how the adoption of 


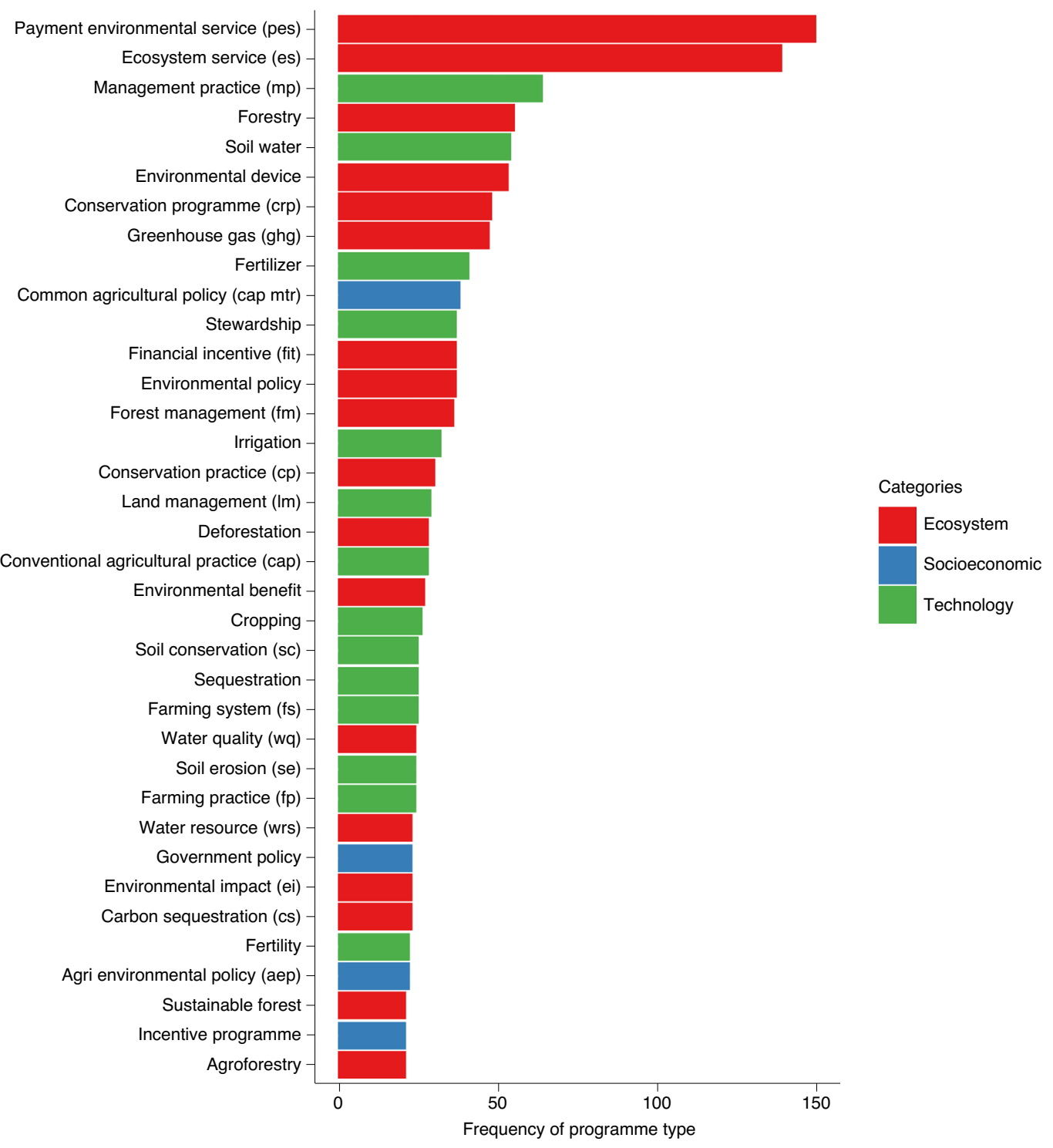

Fig. 1 | Summary of the predominant programme types treated in the literature. All programmes that appeared in more than 20 of the 577 articles are included. Note that the machine learning approach used to tag the articles by topic distinguished terms as used in the articles.

specific practices leads to the desired outcomes, additional analysis was needed. We further limited the subset of papers to only those that had a complete set of links between the incentive-adoptionoutcome pillars (44 papers) (Supplementary Annex 1). The results of this exercise illustrate how many of the papers with the full logic actually addressed multiple incentive categories and outcomes (Fig. 3). This is an important finding, as it bolsters the earlier observation that multipronged, integrated development interventions, both in terms of incentive structure and expected outcomes, are relatively commonplace. It is also important to note that although environmental and profitability outcomes are more or less equally supported by all three incentives, profitability outcomes are more supported by market or non-market incentives.

There is a clear general association between market and non-market incentives and environmental outcomes (Fig. 3). Nearly half of the interventions seen in the full-text review are considering market or non-market incentives and, simultaneously, just over $40 \%$ of the outcomes had an explicit environmental focus (Fig. 4). In general terms, this illustrates that, given appropriate design, market/non-market incentives can be successfully paired with environmental outcomes. Similarly important, it is clear that regulatory-based incentives are either less adequately documented or generally less prevalent in the development community's menu of incentive-based approaches (left side of Fig. 4). Combined with the previous figures linking incentives to multiple outcome types (Figs. 2 and 3), there is support for the idea that development interventions tend to be moving away from simple productivity-enhancing approaches towards a more holistic style of engagement (Fig. 4 right side).

Assessment of the evidence base. For this study, the incentiveadoption-outcome logic is only valid if evidence is present in the full-text review that backs up the claims regarding the outcomes. Although an assessment of evidence is not typically carried out as part of a scoping review ${ }^{12,13}$, we opted to undertake one to understand when and how evidence was used to support assertions regarding inventive-adoption-outcome logic. The review team undertook a subjective assessment to label each study according to the strength of the evidence presented and the quality of the methodology used. 


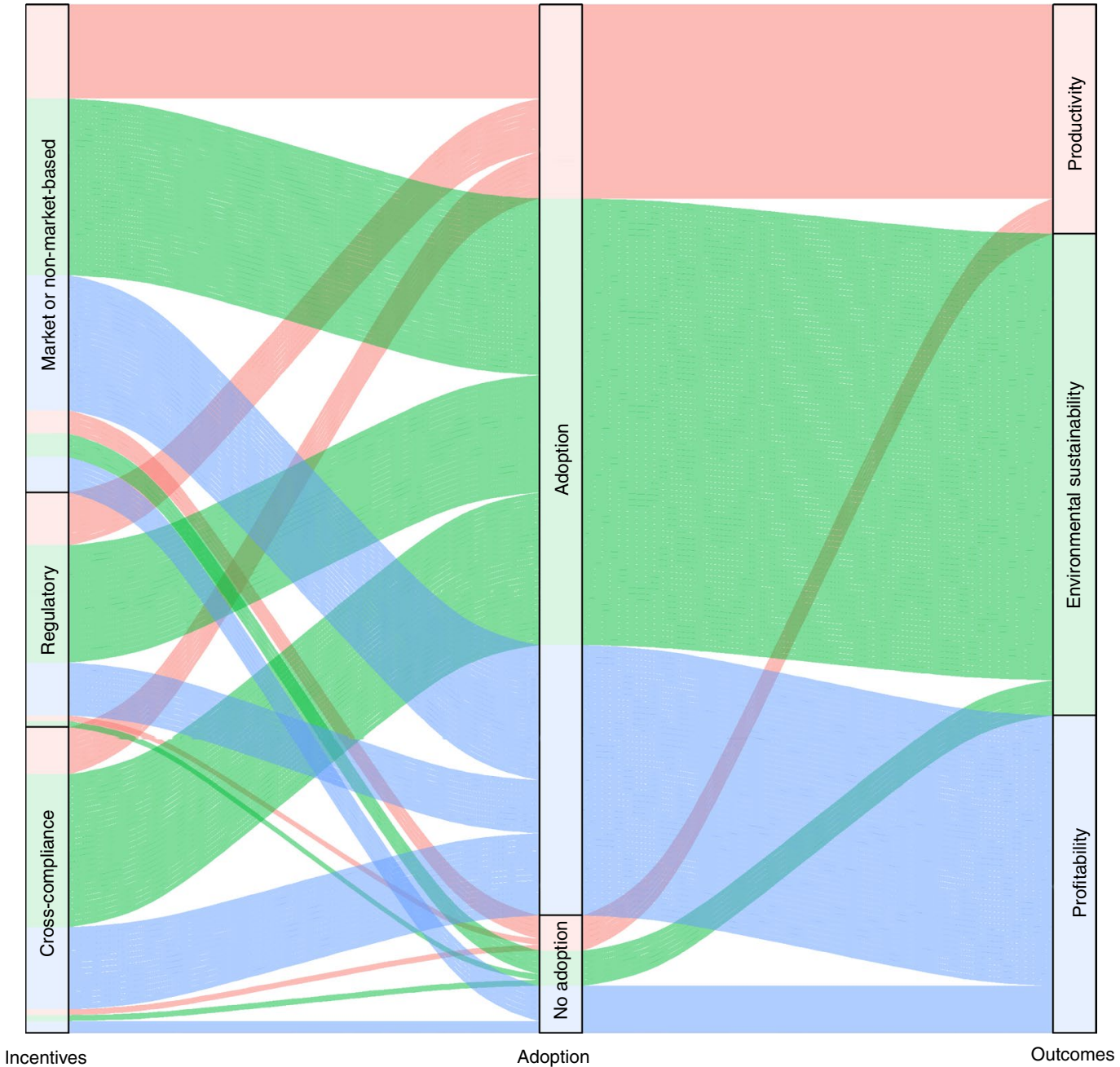

Fig. 2 | Recorded links between incentives, adoption and outcomes. The links are from the subset of 93 articles, colour-coded by outcome.

Assessments of the quality of the methodology are based on the clarity of the research question, justification of the research approach given the question of the study, clear description of the methodology used and robustness of the chosen methodology. Each article was scored on a scale of 1 to 5,1 being the lowest. The findings were summarized by intervention type and outcome (Fig. 5). From the 44 articles, $23 \%$ received the highest score, followed by $32 \%$ with a quality index of 4 and $39 \%$ with a score of 3 . Less than $10 \%$ of the papers were assigned a number lower than 3 , which is why there is no yellow border line in the figure. It is important to notice that one article may be included in more than one cell, as it may include more than one incentive and/or outcome.

Relatively speaking, there was a general lack of clear measurement of outcomes, with only $50 \%$ of the reviewed papers presenting strong evidence (that is, evidence backed by robust analysis and clearly articulated support). Furthermore, evidence for incentiveoutcome relationships is unequally distributed, in terms of the quality and quantity of available evidence, across both the incentive and outcome types (Fig. 5).

This evidence analysis suggests that there is a robust evidence base for environmental outcomes associated with cross-compliance incentives. Likewise, there is strong evidence linking market/ non-market incentives and profitability-related outcomes. Both of these observations are generally consistent with the broader literature. This illustrates the need to substantiate measurement and reporting of evidence, especially in relation to the regulatory-based approaches. The current analysis suggests that understanding of regulatory approaches is generally less present in the literature, even though the methodologies were deemed relatively strong. Regulatory interventions tend to target environmental outcomes, but not exclusively, and are often associated with profitability and productivity-enhancing outcomes (Figs. 2 and 3). Given the general emphasis on cross-compliance and market/non-market approaches, perhaps more attention is needed to examine the scope and efficacy of regulatory approaches.

The available evidence allows us to make some standardized conclusions about the effectiveness of incentives for the adoption of sustainable agricultural practices, and the associated productivity and economic outcomes. However, there is little or no evidence on environmental outcomes, as most of the evidence on this respect is qualitative. Most papers only made an approximation of changes towards improvements in agricultural practices and environmental outcomes through qualitative assessment of farmer's perceptions.

Additional evidence on the effectiveness of incentives in promoting the adoption of sustainable agricultural practices and the associated outcomes is required to move beyond qualitative assessment of farmer's perceptions. In selected papers where there are reliable data and easy monitoring of implemented sustainable systems, there is no systematic follow-up of the environmental impacts. The results are only measurable through the improvements in the productivity and profitability of producers 9 . For measuring potential environmental outcomes, some papers compare adoption rates of farmers receiving 


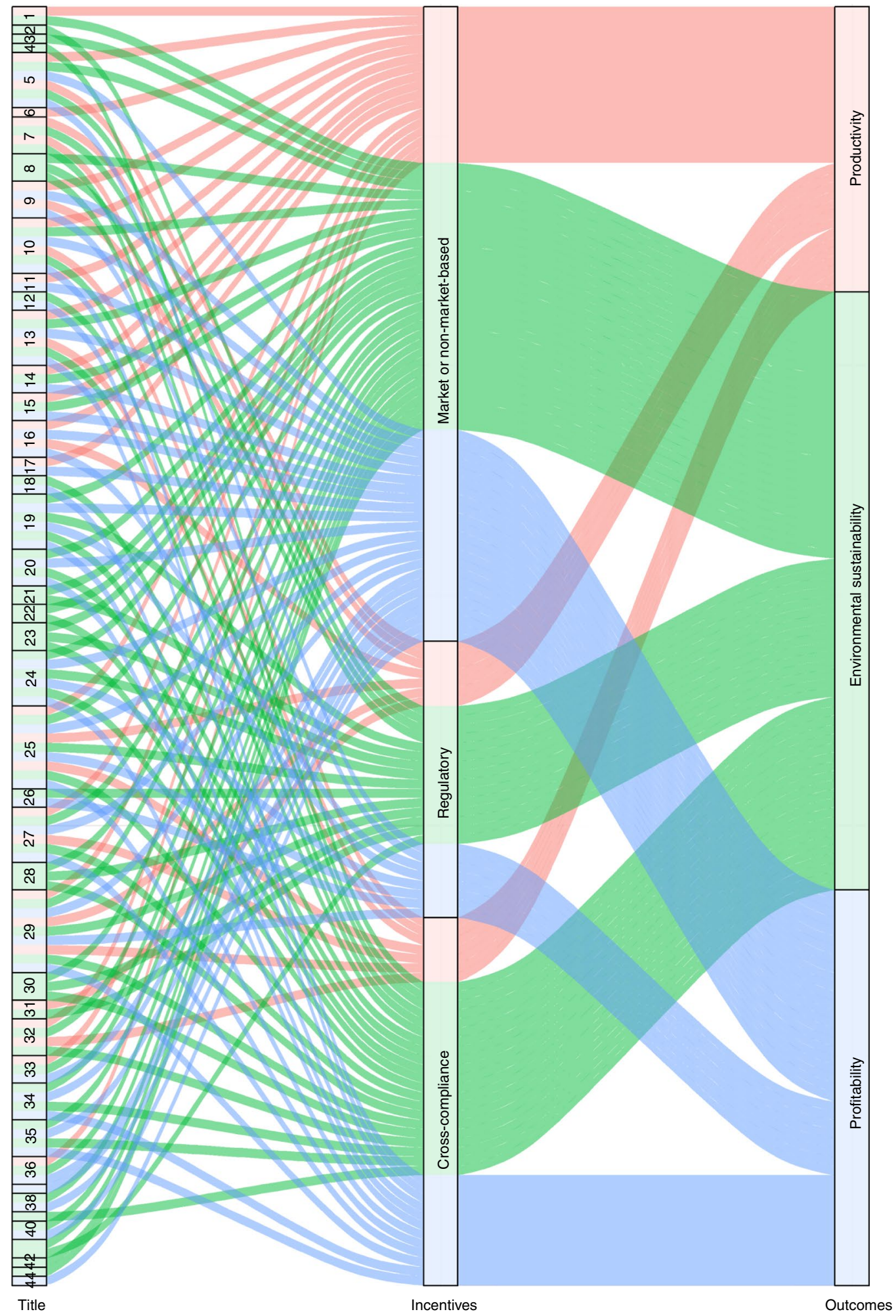

Fig. 3 | Associations between categories of outcomes and the type of incentive used. The 44 full-text reviews are included (read from left to right). See Supplementary Annex 1 for the associated list of papers.

incentives versus non-receiving farmers ${ }^{8,9,12,14}$ or relate socioeconomic characteristics of participants versus non-participants ${ }^{8,15}$.

Most papers simply state the participation rates in terms of the percentage of potential beneficiaries and explain them using influencing factors. Some papers model the adoption according to different incentive levels (such as different tax or levels of payments for environmental services (PES) $)^{10,16-19}$. In those articles, no complete evidence was found connecting incentives with adoption and outcomes. Stronger identification strategies are also needed to uncover the causal effect of the chain of incentives, adoption and outcomes. We found no randomized controlled trial studies in the selected papers, which constitutes an important gap in the literature as these 
a

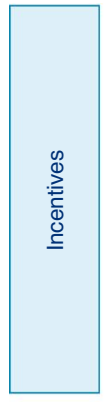

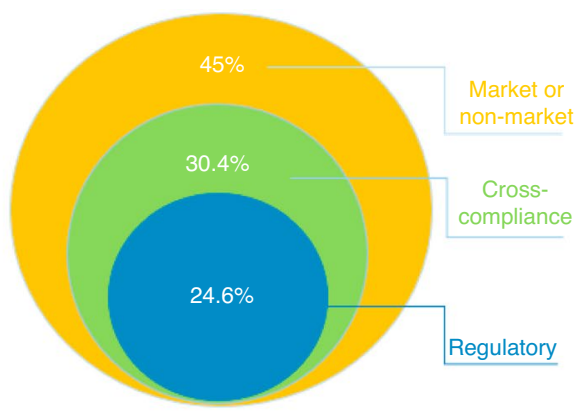

b

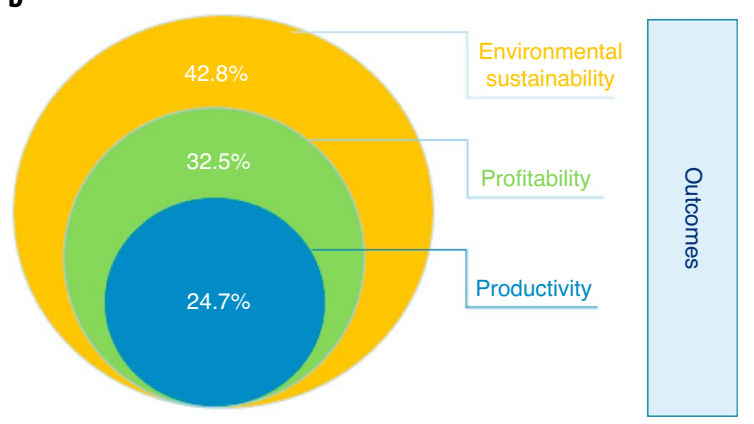

Fig. 4 | Relative proportions of incentives and outcomes. a, Incentives. b, Outcomes. The proportions are expressed as the percentage of the totals across the 44 full-text reviews.

\begin{tabular}{|c|c|c|c|c|}
\hline & & \multicolumn{3}{|c|}{ Outcomes } \\
\hline & & Profitability & Productivity & $\begin{array}{l}\text { Environmental } \\
\text { sustainability }\end{array}$ \\
\hline \multirow{3}{*}{ Incentives } & $\begin{array}{l}\text { Market or non- } \\
\text { market-based }\end{array}$ & & & \\
\hline & Regulatory & & & \\
\hline & Cross-compliance & & & \\
\hline
\end{tabular}

Fig. 5 | Evidence map. The map shows articles reviewed by intervention and outcomes (subset of 44 articles). The sizes of the circles correspond to the number of reviews in each category. The fill colours indicate the level of evidence, with dark blue representing strong evidence and light blue representing weak evidence. The border colours indicate the quality of the methodology; red is used for methodologies that are generally strong and yellow where there are concerns over the methodologies.

kinds of experiments are key to more accurately testing the effectiveness of policy interventions, technologies and practices, taking into account socioeconomic, geographical and environmental influential factors. This scoping review reveals important research gaps: methods to detect causal pathways and to quantify the connections.

Type of incentive. However, despite weaknesses and limitations in the evidence base, the evidence provided by previous programmes on what has worked and what needs to be improved is important to consider when designing future incentive programmes. Looking at the articles reviewed in this scoping review, some interesting aspects for each of the three incentive categories can be highlighted (Fig. 6).

Market and non-market-based incentives. One of the general strengths of market-based incentives is that they offer flexible adoption to promote specific behaviour changes. Examples of this include altering market prices, setting a cap or altering quantities of a particular good, improving the way a market works, or creating a market where none previously existed (for example, water trading ${ }^{20}$. However, one of the weaknesses of market-based incentives and their flexibility is that they can lead to negative social, environmental and economic changes that were unplanned or not in line with the intended strategic direction ${ }^{10}$. For example, subsidies may increase the adoption of intercropping and residue mulching, but these practices may crowd out adoption of zero tillage ${ }^{21}$.

However, a lack of flexibility has been linked to low adoption levels as farmers' previous experiences of using a particular agricultural practice may significantly influence the types of policy instrument they will apply ${ }^{5}$. For example, promoting the use of specific crops for the incorporation of nutrients into the soil is more likely to be adopted by farmers who already practice crop rotation $^{21-23}$. This is particularly pertinent for non-market incentives, for which it is important to understand the interaction between a particular practice and the policy instruments designed to achieve its uptake.

Regulatory incentives. Some studies show that instruments perceived as inflexible or too complex, such as legal regulations, were the least preferred by farmers ${ }^{5}$. Indeed, for regulatory measures, such as forest laws or watershed management programmes, the adoption of practices depends on the effectiveness of law enforcement, supervision and monitoring. For this reason, the adoption of regulatory measures is often linked to accompanying measures such as information sharing, capacity building, technical assistance, training support for the local population and farmer-to-farmer communication networks that build trust and enhance understanding of the potential benefits of conservation practices ${ }^{24}$. Agricultural extension services, both public and private, have been shown to have a positive impact on adoption rates s, $^{5,72,15,23,25-28}$. Connecting these programmes with national extension systems can result in a significant change in agricultural sustainability.

To increase their effectiveness, regulatory measures are often linked to economic incentives including forest trade quotas, certification, access to rural credits or benefits in insurance markets. For example, voluntary community-based programmes are often coupled with short-term financial support to incentivize participation $^{25,29}$. To improve efficiency in the adoption of the promoted practices, flexible payments may be preferred as participation costs 


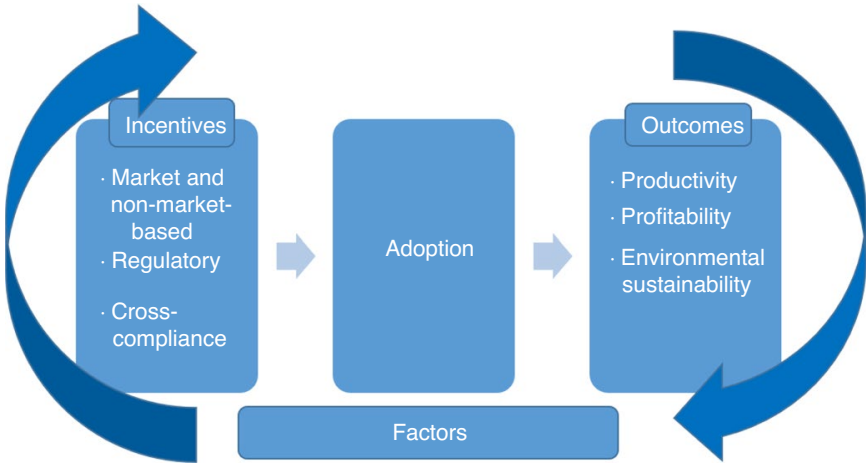

Fig. 6 | Pillars and linkages. The diagram illustrates the pathways between the three pillars.

and expected benefits differ depending on individual farmers and geographical location ${ }^{16}$.

Cross-compliance incentives. Cross-compliance incentives help overcome the barriers that make the adoption of sustainable practices unattractive, such as large up-front adoption costs, lack of capital, restricted access to financial markets and the need to provide for the household's short-term economic needs. They are based on the hypothesis that incentives should at least compensate for the income loss or additional costs of adopting sustainable practices; and that there should be clear monitoring processes that ensure compliance with the conditionality (the adoption of the sustainable practice).

The main cross-compliance incentives are PES or agri-environment payments. These are incentives offered to farmers, or landowners, in exchange for managing their land to provide some type of ecological service, including water quality, forestry, soil erosion and air pollution. In the case of resource conservation in the Ecuadorian Andes, it was shown that when conservation technologies were offered in conjunction with measures that enhance the short-term profitability of agriculture (such as new crops, biological barriers and improved agricultural production), the adoption of conservation practices increased significantly. Similar results were found in the Nepal Knowledge Based Integrated Sustainable Agriculture and Nutrition (KISAN) project ${ }^{30}$. These two examples reflect the broader finding that in most of the reported PES case studies, socioeconomic and environmental outcomes have been positive $e^{8,15,30}$, especially if the PES is accompanied by technical assistance ${ }^{7,12}$.

\section{Discussion}

The decision by farmers to adopt sustainable agricultural practices in response to incentive programmes is not a binary process. Adoption is a continuum that depends on many factors: the conditions of the programme, the incentives offered, the environmental preferences, personal perspectives, experience and education of farmers ${ }^{4}$. Farmers' decisions are shaped by personal opinions, such as preferences over conservation measures, beliefs about the programme and degrees of risk aversion ${ }^{21,31}$. Factors such as income levels, asset ownership, age, and access to other economic opportunities also correlate with the decision to adopt, as they affect the capacity of the target population to reap benefits from the progra $\mathrm{mme}^{5-7,12,29,32-34}$. The decision to adopt is also affected by the biophysical characteristics of the land plot, and the institutional and policy context. Even agricultural market trends affect producers' decisions to adopt agricultural practices ${ }^{3,6}$. The variety of factors that contribute to the adoption of sustainable agricultural practices necessitates the consideration of context in policy design and the use of differentiated policy instruments ${ }^{16}$.
Incentives across the spectrum. Direct economic benefits, increased productivity or profitability seem to be the essential condition for the adoption of sustainable practices in the short term ${ }^{7}$. Regardless of the incentive type, adoption rates are higher when programmes offer short-term economic benefits than those solely aimed at providing a positive ecological outcome. For example, restrictive land-use-change programmes, such as those induced by climate change, which modify the incentives for engaging in agricultural production, agroforestry and other land uses have higher adoption rates when they are connected with an improvement in income $e^{13,15}$.

Nevertheless, and independent of the incentive type, in the long term it seems that one of the strongest motivations for farmers to adopt and maintain sustainable practices is the perceived positive outcomes of these practices for their farm or the environment ${ }^{8-11}$. For example, the greatest motivating factor for participation in a forest conservation scheme in Kenya was the 'will to conserve', influenced by the local communities' concern for the degradation of their environment and their perceived dependency on natural resources ${ }^{11}$. The will to participate was based on the perceived benefits of conservation, especially changes in water availability, which were reinforced by the potential benefits of new income-generating activities. This suggests that incentives can lead to the adoption of sustainable practices and have positive effects on ecological services, even without direct payments. If participants perceive future benefits of sustainable practices, the likelihood of adoption increases ${ }^{15,29}$.

Compulsory or voluntary incentives. The likelihood of a farmer adopting the associated sustainable agricultural practice depends on whether the incentive is compulsory or voluntary ${ }^{5}$. Voluntary incentive programmes, such as market and non-market-based incentives or certification schemes (for example, carbon footprints, water footprints, organic farming), have a high degree of uncertainty as they depend on the decision of farmers to adopt sustainable practices. In general, if the economic incentives or payment levels do not offset the costs of adoption (cover opportunity costs of changing production techniques or for the most productive land uses), farmers will rarely switch to the desired practices. However, if payment levels compensate, or overcompensate, for income losses and additional costs, then the willingness of farmers to adopt is normally high.

In contrast, the uptake of sustainable agricultural practices due to compulsory incentives is fairly certain. Regulatory measures, such as legal regulations, reduce uncertainty by imposing sanctions for non-compliance. The adoption of regulatory measures depends on the effectiveness of law enforcement, supervision and monitoring; however, if institutions are able to enforce the sanctions, the uncertainty surrounding adoption is low or non-existent ${ }^{28}$.

The degree of uncertainty in the adoption of sustainable practices is closely linked to contradictions between the preferences of farmers and society. Farmers may prefer the short-term financial support and flexibility offered by voluntary incentive programmes, which, being voluntary, tend to create more uncertainty in the achievement of the programme's environmental goals. This can conflict with society's preference for longer-term instruments, such as legal regulations, which tend to reduce uncertainty in the achievement of outcomes.

Broader contextual factors. Throughout all stages in the incentiveadoption-outcome chain, wider contextual factors play an important role. Ignorance of the practices promoted and the opportunity costs from foregone activities due to limitations on land use and restrictions on the use of some management practices may deter participation by some farmers ${ }^{16,29,35}$. Complexity, inflexibility and complicated procedures are also salient obstacles for participation $^{5,15,16}$. Therefore, the timescale, desired outcome and target population must be considered in all aspects of sustainable agricultural policy, from design to implementation to assessment. 
The effectiveness of a particular incentive, and the likelihood of adoption, varies depending on the agricultural practice that one wants to promote and the associated (predicted) outcomes ${ }^{5}$. Within this, there are a multitude of factors that determine the perceived and actual costs and benefits, both direct and indirect, of adopting sustainable practices. The attributes of the programme determine the likelihood of adoption, which is influenced by the perception of an improvement in net benefit and access to alternative markets. In some cases, positive outcomes-such as increases in yields-may not be enough to compensate for the higher input and capital requirements of the proposed agricultural interventions ${ }^{36}$. Therefore, economic incentives are necessary and need to be large enough to compensate for the opportunity cost of change, taking into consideration that the effects on outcomes take time to realize.

Outcomes may not be obvious in the short term; there may be a substantial time lag associated with the uptake of new practices and the expected results. For example, in examining fruit farmers in Uruguay, it was found that even with clear evidence of the adoption of specific practices, the expected outcomes took different times to materialize ${ }^{37}$. In the case of productivity, there may actually be negative consequences in the short run. Therefore, the link between adoption and outcome requires consideration of the time horizon.

Broader findings to boost adoption. The important complementary role of technical assistance and extension services also emerges strongly from several papers within this scoping review. Technical assistance, training and extension agents, both public and private, enhance the rate of adoption for all incentive mechanisms $s^{7,12,15,22,23,27,28}$. Beyond this, additional assistance programmes boost short-term benefits, and ensure the long-term sustainability and inclusiveness of the incentives. For example, where PES incentives (cross-compliance) were accompanied by additional technical assistance, the sustainability of the sustainable outcomes beyond the life of the PES contract could be expected ${ }^{7,12,27,29,37}$. The availability of technical support or other complementary practices is particularly pertinent to regulatory incentives, for which a key criticism is their complexity. In these cases, an increased knowledge and understanding of environmental services and regulations can boost adoption ${ }^{5,24}$. Overall, the provision of information and technical assistance regarding sustainable practices can foster a higher take-up rate of the programmes and a broader retention of the practices s $^{5,11,15,23,38}$.

Beyond this, training programmes and the introduction of locally adapted technologies can contribute to changing practices even without other types of incentives or interventions if they present economic advantages for their users. Adoption can be enhanced by the promotion of sustainable farming activities by a development organization or farmers' associations, coupled with marketing activities ${ }^{15,25}$.

Trade-offs in outcomes. Sustainable policies should seek to adopt an integrated approach that addresses both short-term priorities such as profitability, while simultaneously working towards long-term environmental outcomes. The design of these instruments often entails trade-offs among the long-term outcomes, different environmental objectives, and equity and efficiency goals.

In designing sustainable agricultural policy, it may be necessary to prioritize and make trade-offs between different environmental objectives. For example, quantity-based market-based incentives (MBIs) such as water trading may reallocate water to 'high-value' users, such as mining, manufacturing and electricity production from 'low-value' users, such as agricultural producers ${ }^{25}$. As some high-value users produce high levels of greenhouse gas emissions, achieving the goals for water use may come at a cost for the goal of reducing greenhouse gas emissions. In such cases, an additional measure, such as a regulatory mechanism, may be put in place to minimize the potential trade-off ${ }^{17}$. The design of sustainable agricultural policies, and their incentives, therefore requires a broad assessment and consideration of the potential outcomes, and their consequences.

In some cases, trade-offs in socioeconomic and environmental outcomes may be required, as effectively attaining environmental outcomes may deepen economic inequality. The evidence shows that targeting wealthier landowners can produce greater impacts on environmental outcomes ${ }^{29}$. Wealthier landowners may be able to have a higher impact on environmental outcomes than poorer farmers who face much higher opportunity costs from adopting sustainable practices, chief among them subsistence production. If programmes are targeted at regions with higher wealth and environmental degradation to maximize the achievement of environmental goals, it is likely that a larger percentage of wealthier owners will enrol in the programme and the poorest ones will be excluded. If financial incentives are provided, the income of the wealthier landowners will further increase, enhancing income disparities. Consequently, it may not always be possible to simultaneously achieve different environmental and equity development goals with the same policy tool. Indeed, several papers in this scoping review point out the potential for conflict associated with equity and efficiency ${ }^{13,29}$, a subset of which suggested that the environmental efficiency of these approaches should justify their adoption in certain instances. In general, the alignment of equity and efficiency will occur only if the geographical location of the programme overlaps with the location of poor farmers.

An alternative approach is to target incentive programmes at the lands most vulnerable to land-use change or farmers more reluctant to adopt sustainable practices to promote additionality. Additionality measures the net result from an intervention and is defined as the product of environmental service provision (for example, hydrological services, biodiversity conservation, carbon sequestration and landscape beauty services) and deforestation probability, resulting from an $\mathrm{PES}^{22}$. The question therefore is if and when incentive programmes are necessary to encourage adoption. Farmers who are more likely to adopt incentive programmes are often located in regions in which deforestation risks are lower, have stronger preferences for conservation programmes, the opportunity costs from adopting sustainable practices are lower, or the net benefits of adoption are high regardless of the economic incentives. Hence, the incentives might not be the real driver for adopting sustainable practices, and adopters might participate in the programme regardless of the incentives. Incentive programmes should therefore target vulnerable areas to ensure additionality of the programme and the most effective use of resources.

Furthermore, the measure of outcomes should account for the trade-offs among different types of incentives-or how different incentive types could complement one another to achieve the desired outcomes. Indeed, multipronged programmes that incorporate social, economic and productivity components are more likely to succeed in developing countries. This echoes the findings of Giller et al. ${ }^{39}$, whose review of conservation agriculture and sustainable intensification technologies and practices suggests that a systems approach, combining the tools of experimentation and simulation modelling, should be adopted to evaluate multiscale trade-offs and synergies. This will provide the toolbox and methods to allow informed choices of technologies and practices tailored to local conditions (Box 3).

Recommendations. Incentive programmes need to be well targeted, effective and efficient while taking into account spatial differences, differences in economic activities and types and the number of economic, social and environmental outcomes pursued, as well as budget limitations. The design of such programmes, which are also flexible, simple to implement and cost effective, is not an easy task and requires a collective effort and good data. A challenge for 


\section{Box 3 | Policy recommendations}

Notwithstanding the limitations and gaps found in the literature, the following is a set of tested principles to follow when designing interventions or policy instruments. These are based on the most solid evidence found on the effectiveness of incentives to motivate the adoption of sustainable practices that, in turn, led to better indicators of productivity, profitability and environmental sustainability of farms under different production systems and conditional factors.

Balance the incentives and outcomes. Incentives must be high enough to motivate a change in production practices. This is because productivity and profitability gains can be insufficient to compensate for the total cost of the initial capital requirements and any unexpected costs of the proposed agricultural interventions.

Know your farmers. The likelihood of farmers adopting sustainable agricultural practices will vary depending on their experience, education, access to information and level of risk-aversion. Policymakers must be familiar with the farmers, and tailor the incentive programmes for them by incorporating the range of personal, political, institutional and biophysical factors into the design of the programme.

Keep it simple. Instruments should be simple to understand and communicate given that farmers dislike instruments that are too complex (such as some legal regulations) and are therefore less likely to adopt them. Besides, complexity makes instruments harder to communicate and more expensive to adopt or enforce.

Complement. Single interventions are less likely to succeed, hence the need to use a combination of policy instruments. For example, the provision of technical assistance and extension services contributes to the understanding of farmers and helps them adopt proposed practices.

Behavioural preferences matter. Given that people have a tendency to follow the behaviour of others, farmers' preferences should be taken into account when designing incentives, acknowledging that they vary depending on the target population.

Be prepared for a long time horizon. The time horizon depends on the agricultural practice, the production system and the biological cycle. This means the opportunity cost of time has to be considered and financial tools have to be put in place so that cash flow problems do not jeopardize the intervention.

Create an enabling environment. Incentives that make the adoption of sustainable practices attractive depend heavily on an enabling economic and financial environment. Beyond incentives, it is necessary to improve the general conditions that influence agricultural systems. There are many factors that influence the capacity and willingness of farmers to invest in land, water and forest conservation and to pursue sustainable practices such as agricultural institutions, policies and regulations, social protection, infrastructure and markets, prices, off-farm employment opportunities and structural poverty.

the future is to reduce the cost and allocate more resources to the collection of detailed data. This is a condition for the estimation of environmental services such as biodiversity, carbon services (that require information on the amount of stored carbon before and after an adopted practice) or hydrological services (that require information on site-specific soil characteristics, vegetation cover, slope, distribution and intensity of precipitation). Similarly, the quality and availability of data are frequently inadequate for more precise measures of the cost of participation in incentive programmes.

Beyond the specific incentives examined in this scoping review, it is still necessary to improve the general conditions influencing agricultural systems and practices for sustainable outcomes of the whole sector (Box 3). Agricultural institutions, policies and regulations, social protection, infrastructure and markets, relative prices, off-farm employment opportunities, structural poverty and the scarcity of asset endowments all influence the capacity and willingness of farmers to invest in land, water and forest conservation and to pursue sustainable practices. These are discussed in some papers as conditioning factors. Nevertheless, there is still the need to better understand the interrelationships between these factors, incentives, adoption and outcomes.

\section{Methods}

Evidence synthesis methodology and protocol pre-registration. This scoping review was prepared following guidelines from the Preferred Reporting Items for Systematic Reviews and Meta-Analyses extension for scoping reviews (PRISMA-ScR) ${ }^{40}$. The methodology for this scoping review follows the framework established in the PRISMA extension for scoping reviews, which builds on the Joanna Briggs Institute's guidelines ${ }^{41}$ for conducting scoping reviews. Note that the current CEE Guidelines for Systematic Reviews in Environmental Management ${ }^{42}$ (version 4.2, March 2013) do not provide recommendations for the number of people who should conduct eligibility screening, although the Guidelines implicitly suggest that a single screener may be acceptable provided that an assessment of screener reliability is conducted. According to the latest CEE evidence synthesis protocols published in Environmental Evidence journal (January-July 2017), screening by a single person, subject to a check of screener reliability using a subset of articles, is the currently practiced approach in most cases ${ }^{42}$.

Scoping reviews are designed to summarize studies of varying methodological designs while highlighting key areas for future research and engagement ${ }^{43,44}$. This scoping review leveraged a data-science framework to accelerate the work within each of the individual steps, which are described below. This framework comprises five steps: identifying the research question; identifying relevant studies; study selection; extracting and charting the data; and collating, summarizing and reporting the results. The protocol used in this scoping review was registered on the Open Science Framework and is available in Supplementary Annex 2 (ref. ${ }^{45}$ ).

The guiding question for this scoping review was, "What are the market, non-market, regulatory and compliance incentives or compulsory/voluntary programmes for farmers to adopt environmentally sustainable practices?".

This study spans both developed and developing world contexts and characterizes how the incentives associated with different instruments may affect adoption given local institutional, environmental and socioeconomic factors. It was not limited by geography or country status.

The goal of this scoping review was to make recommendations about how to promote environmental practices for more sustainable, and at the same time competitive, agricultural production systems. This scoping review looks at the overall landscape of evidence of these instruments and their effectiveness in achieving higher levels of productivity, profitability and equity.

Information sources, searches and citation management. A comprehensive search strategy was developed to identify all available research pertaining to the market, non-market, regulatory and cross-compliance incentives for farmers to adopt environmentally sustainable practices. Search terms included variations of the key concepts in the research question: farmers, incentives, implementation of agricultural practices and environmental impact (see Appendix A of Supplementary Annex 2 (ref. ${ }^{45}$ ) for a presentation of the search strategy in its entirety such that it may be reproduced in CAB Abstracts).

Research synthesis experts conducted searches of the following electronic databases: CAB Abstracts (access via CAB Direct); Web of Science Core Collection (access via Web of Science); Scopus (access via Elsevier); and EconLit (access via EBSCOhost). A search of grey literature sources was also conducted. The grey literature searches were conducted using custom web-scraping scripts. The search strings were tested per website before initiating web-scraping. An existing Google Chrome extension was needed to scrape dynamically generated websites.

A data science team supported much of our process. The results from the databases and the grey literature searches were combined and deduplicated using a Python script. Duplicates were detected using title, abstract and same year of publication where year of publication was a match, where title cosine similarity was greater than $85 \%$ and where an abstract's cosine similarity greater than $80 \%$ or one of the abstracts (or both) was empty. When duplicates were found, the 
citation priority order was Scopus, CAB Abstracts, Web of Science and then grey literature sources.

Following deduplication, each citation was analysed using a boosted machine learning model. The model added more than 30 new metadata fields that identified population, geographies, interventions, study design type and outcomes of interest. This allowed for accelerated identification of potential articles for exclusion at the title/abstract screening stage.

The combined search results and new metadata were shared with the research team using Excel spreadsheets and through the screening platform Covidence. The metadata was made available in Covidence ${ }^{46}$ in the abstract field delineated by hash-tags (\#\#\#) using a global open-source converter that can translate existing bibliographic data from a .csv format to .ris format.

Study selection and eligibility criteria. The systematic review software Covidence was used for title, abstract and full-text screening decision-making. Article screening took place in three phases: title screening, abstract screening and full-text screening. At all screening stages, citations were screened for relevance against the following inclusion and exclusion criteria; reasons for exclusion were documented at the full-text screening phase.

Citations were included in this scoping review if they met all of the inclusion criteria listed in Box 2.

Exclusion criteria were the inverse of the inclusion criteria. Each citation that met all of the inclusion criteria at the title and abstract and full-text screening phases was included, and each citation that met one of the exclusion criteria at the title, abstract, or full-text screening phases was excluded.

Title/abstract screening was initiated for the 17,936 articles with two independent reviewers reviewing each citation. After the first 200 articles, due to the very large number of citations to screen and because there was a strong degree of inter-rater reliability, a rapid review, single-screener methodology was adopted for all of the remaining citations. The rapid review process comprised a title review followed by an abstract review of included citations. After this first stage, 1,792 papers were selected; of these, 1,694 were found in scholarly databases and 98 were found in grey literature sources.

The inclusion criteria were complex and nuanced, particularly the connection of the adoption of incentives to sustainability outcomes, and the degree to which a study focused on incentives or their adoption. These matters of focus and connection could not be captured by a search strategy alone, but required human judgement. This resulted in a large number of irrelevant results from the initial searches. Among the 1,215 articles that were excluded at the abstract screening phase, 442 were excluded because they did not include an explicit analysis of the impact of the incentives on income, production, productivity, profits and/or environmental sustainability and 418 were excluded because there was no explicit focus on incentives for sustainable environmental practices. For more information, the PRISMA flow diagram (Supplementary Fig. 1) shows the steps followed for the screening process and selection exercise.

Following Waffenschmidt et al., we conducted a double-blind pre-test of ten articles and then assessed inter-rater reliability using the Fleiss Kappa indicator to test for inter-rater reliability in the full-text screening ${ }^{47}$. This indicator is a statistical measure for assessing the reliability of agreement between a fixed number of raters when classifying a number of items. The measure calculates the degree of agreement in classification over that which would be expected by chance.

After calculating the indicator, we can say that the level of potential bias of a single-screener method introduced here is not significant, given that the kappa value of at least 0.61 indicates substantial agreement and we have a value of 0.7 .

In the next selection round, the single-screener methodology was also used, maintaining the same inclusion/exclusion criteria. After this process, 577 citations were kept; of these, 551 were found in scholarly databases, 27 were found in grey literature sources and one was removed as a duplicate. The proportion of resources from the grey literature versus scholarly databases remained consistent throughout the screening process, with $4.48 \%$ of the resources originally identified and $4.88 \%$ of the resources eligible for full-text inclusion coming from the grey literature.

Because a very large set of citations was included for full-text screening, a semi-structured, stratified randomized sample of 99 citations was selected. Our early review process suggested that certain categories of papers (for example, regarding forestry policy) were more common than others. In an effort to capture relevant citations in less prevalent categories, we used smooth inverse document frequency and cosine distances to create a vector space representation of the contents of the titles, key words and abstracts of the 577 articles. We then clustered the vectors-each article is represented as a vector of terms and frequencies-into 20 clusters using Ward's method for hierarchical clustering ${ }^{48}$. A threshold of 20 clusters resulted in clusters ranging in size from 5 to 300 articles. The basis of cluster composition for the smaller clusters was moderately discernible (for example, ecosystem services and water-related), whereas the basis for agglomeration of the larger clusters was not immediately evident. We then implemented a stratified random sampling process to identify the set of 99 articles from the 20 clusters as a function of cluster size. The Orange Data Mining Toolbox was used for the analysis ${ }^{49}$. Finally, 6 of these 99 articles were not included as they were written in a language not spoken by any of the authors of this research or because of their unavailability.
Data extraction. A data extraction template was developed based on Barrett et al. to document the data, study type and context of each citation, and all themes of interest: incentives, outcomes, measurements of impact and the cost of intervention ${ }^{50}$. The data extraction template was tested by the review team before use to make sure that all the necessary information for the analysis of the research question was included. Data was extracted by the reviewers using an excel worksheet including the following information:

- A categorization of incentives by market, non-market, regulatory and compliance incentives for farmers.

- Type of outcomes covered in question of the study: environmentally sustainable, profitability and productivity.

- Other information relevant for the analysis including characteristics of the stakeholders, commodity (crop, pasture, aquaculture, forestry), data (cross-section, panel, survey, interviews, policy analysis), methodology (econometrics, systematic review, meta-analysis, randomized controlled trials), study (quantitative or qualitative)

- Questions relating to the quality of the paper, the link between incentives and adoption, measurement of the incentive, the type of outcome and its measurement and cost of the incentive.

The retrieval of hundreds of PDFs for full-text screening is a repetitive and time-consuming task. A Python script was created that would handle the repetitive tasks of PDF discovery, download and file renaming using Google Scholar (the code is available in GitHub). The script read the bibliographic data from an Excel spreadsheet and then executed a script to retrieve the full-text PDF. The possible returning results are 'not found, 'backed by a paywall', 'available for download' or 'available for request'. If the article is spotted in the search results, the download link is clicked, and the article will be auto-renamed and marked as being downloaded. This process significantly cut down the time needed to retrieve PDFs, and on average 200 PDFs were searched and retrieved in 3-4h.

The collation, summary and report of the results. This research was based on three pillars-incentives, adoption and outcomes-in looking at the question of how the incentives farmers receive influence the adoption of good environmental practices. These three pillars are important in answering the question, but the links between them are crucial as well. The connection between the incentives and actual adoption, as well as the connection between adoption and the outcomes identified play a key role in this scoping review (Fig. 6).

Incentives were categorized as market-based and non-market-based, regulatory and cross-compliance incentives for farmers to adopt sustainable environmental practices and integrated risk management systems (crop insurance, catastrophic insurance, price options, mitigation and adaptation programmes and so on) in a voluntary or compulsory way. The outcomes were identified as practices adopted by farmers, and their impact on the multiple objectives of environmental sustainability, increased productivity and profitability.

An appraisal for quality was done for the 44 articles that passed the inclusion selection process, were part of the sample chosen and had the link between incentives and adoption, and adoption and outcomes.

The assessment was done by the authors of this research from a scale of 1 to 5, 1 being the lowest. The quality assessment was based on the clarity of the research question, justification of the research approach given the question of the study, clear description of the methodology used and robustness of the chosen methodology. However, it was not used to further exclude papers. From the 44 articles, $23 \%$ received the highest score, followed by $32 \%$ with a quality index of 4 and $39 \%$ with a 3 , less than $10 \%$ of the papers were assigned a score of less than 3 . The previously completed screening process was key in ensuring that articles that did not have substantive evidence were not included in this last stage.

\section{Data availability}

The data that support the findings of this study are available from the corresponding author on reasonable request.

Received: 20 December 2019; Accepted: 4 September 2020; Published online: 12 October 2020

\section{References}

1. Wheaton, E. \& Kulshreshtha, S. Environmental sustainability of agriculture stressed by changing extremes of drought and excess moisture: a conceptual review. Sustainability 9, 970 (2017).

2. Herrera, H. Resilience for whom? The problem structuring process of the resilience analysis. Sustainability 9, 1196 (2017).

3. Teklewold, H., Kassie, M. \& Shiferaw, B. Adoption of multiple sustainable agricultural practices in rural Ethiopia. J. Agric. Econ. 64 597-623 (2013)

4. Barnes, A. et al. Influencing factors and incentives on the intention to adopt precision agricultural technologies within arable farming systems. Environ. Sci. Policy 93, 66-74 (2019). 
5. Schirmer, J., Dovers, S. \& Clayton, H. Informing conservation policy design through an examination of landholder preferences: a case study of scattered tree conservation in Australia. Biol. Conserv. 153, 51-63 (2012).

6. Caviglia-Harris, J. L. Sustainable agricultural practices in Rondônia, Brazil: do local farmer organizations affect adoption rates? Econ. Dev. Cult. Change 52, 23-49 (2003).

7. Garbach, K., Lubell, M. \& DeClerck, F. A. J. Payment for ecosystem services: the roles of positive incentives and information sharing in stimulating adoption of silvopastoral conservation practices. Agric. Ecosyst. Environ. 156, 27-36 (2012).

8. Winters, P., Crissman, C. C. \& Espinosa, P. Inducing the adoption of conservation technologies: lessons from the Ecuadorian Andes. Environ. Dev. Econ. 9, 695-719 (2004).

9. Gibbon, P. \& Bolwig, S. The Economics of Certified Organic Farming in Tropical Africa: A Preliminary Assessment (DIIS, 2007); https://www.econstor. eu/handle/10419/84534

10. Khanna, M., Isik, M. \& Zilberman, D. Cost-effectiveness of alternative green payment policies for conservation technology adoption with heterogeneous land quality. Agric. Econ. 27, 157-174 (2002).

11. Himberg, N., Omoro, L., Pellikka, P. \& Luukkanen, O. The benefits and constraints of participation in forest management. The case of Taita Hills, Kenya. Fennia 187, 61-76 (2009).

12. Zapata, Á., Murgueitio, E., Mejía, C., Zuluaga, A. F. \& Ibrahim, M. Effects of payments for environmental services in the adoption of silvopastoral systems in cattle landscape in the middle watershed of Río La Vieja, Colombia. Agroforest. Am. 45, 8 (2007).

13. Wunder, S., Engel, S. \& Pagiola, S. Taking stock: a comparative analysis of payments for environmental services programs in developed and developing countries. Ecol. Econ. 65, 834-852 (2008).

14. Marenya, P., Nkonya, E., Xiong, W., Deustua, J. \& Kato, E. Which policy would work better for improved soil fertility management in sub-Saharan Africa, fertilizer subsidies or carbon credits? Agric. Syst. 110, 162-172 (2012).

15. Cole, R. J. Social and environmental impacts of payments for environmental services for agroforestry on small-scale farms in southern Costa Rica. Int. J. Sustain. Dev. World Ecol. 17, 208-216 (2010).

16. Wünscher, T., Engel, S. \& Wunder, S. Spatial targeting of payments for environmental services: a tool for boosting conservation benefits. Ecol. Econ. 65, 822-833 (2008).

17. Wei, Y., Chen, D., Hu, K., Willett, I. R. \& Langford, J. Policy incentives for reducing nitrate leaching from intensive agriculture in desert oases of Alxa, Inner Mongolia, China. Agric. Water Manag. 96, 1114-1119 (2009).

18. Lungarska, A. \& Chakir, R. Climate-induced land use change in France: impacts of agricultural adaptation and climate change mitigation. Ecol. Econ. 147, 134-154 (2018).

19. Sheng, J., Qiu, H. \& Zhang, S. Opportunity cost, income structure, and energy structure for landholders participating in payments for ecosystem services: evidence from Wolong National Nature Reserve, China. World Dev 117, 230-238 (2019)

20. Kiem, A. S. Drought and water policy in Australia: challenges for the future illustrated by the issues associated with water trading and climate change adaptation in the Murray-Darling Basin. Glob. Environ. Change 23, 1615-1626 (2013).

21. Ward, P. S., Bell, A. R., Parkhurst, G. M., Droppelmann, K. \& Mapemba, L. Heterogeneous preferences and the effects of incentives in promoting conservation agriculture in Malawi. Agric. Ecosyst. Environ. 222 67-79 (2016).

22. Weltin, M. \& Zasada, I. Farmers' choices of adopting and coupling strategies of sustainable intensification-evidence from European farm level data. In 13th European International Farming Systems Association (IFSA) Symposium, Farming Systems: Facing Uncertainties and Enhancing Opportunities 1-11 (IFSA, 2018)

23. Reid, G. H. Building resilience to climate change in rain-fed agricultural enterprises: an integrated property planning tool. Agric. Hum. Values 26, 391-397 (2009).

24. Ariti, A. T., van Vliet, J. \& Verburg, P. H. Farmers' participation in the development of land use policies for the Central Rift Valley of Ethiopia. Land Use Policy 71, 129-137 (2018).

25. Kingwell, R., John, M. \& Robertson, M. A review of a community-based approach to combating land degradation: dryland salinity management in Australia. Environ. Dev. Sustain. 10, 899-912 (2008).

26. Cotler Ávalos, H., Cram Heydrich, S., Martinez Trinidad, S. \& Bunge, V. Conservation practices assessment in forest soils of Mexico: the case of the ditches. Investig. Geográf. https://doi.org/10.14350/rig.47378 (2015).

27. Nakano, Y., Tanaka, Y. \& Otsuka, K. Impact of training on the intensification of rice farming: evidence from rainfed areas in Tanzania. Agric. Econ. 49, 193-202 (2018).

28. Santiago, T. M. O., Caviglia-Harris, J. \& Pereira de Rezende, J. L. Carrots, sticks and the Brazilian Forest Code: the promising response of small landowners in the Amazon. J. For. Econ. 30, 38-51 (2018).
29. Bremer, L. L., Farley, K. A. \& Lopez-Carr, D. What factors influence participation in payment for ecosystem services programs? An evaluation of Ecuador's SocioPáramo program. Land Use Policy 36, 122-133 (2014).

30. Kumar, A. et al. Adoption and Diffusion of Improved Technologies and Production Practices in Agriculture: Insights from a Donor-Led Intervention in Nepal (IFPRI, 2018); https://go.nature.com/3i8xusc

31. Adhikari, R. K., Kindu, M., Pokharel, R., Castro, L. M. \& Knoke, T. Financial compensation for biodiversity conservation in Ba Be National Park of Northern Vietnam. J. Nat. Conserv. 35, 92-100 (2017).

32. Alix-Garcia, J. M., Sims, K. R. E. \& Yañez-Pagans, P. Only one tree from each seed? Environmental effectiveness and poverty alleviation in Mexico's payments for ecosystem services program. Am. Econ. J. Econ. Policy 7, $1-40$ (2015).

33. Vollmer-Sanders, C., Wolf, C. \& Batie, S. S. Financial and environmental consequences of a voluntary farm environmental assurance program in Michigan. J. Soil Water Conserv. 66, 122-131 (2011).

34. Ipe, V. C. A group incentive program for farmer adoption of best practices: an application to the nitrate pollution problem in central Illinois. In American Agricultural Economics Association (AAEA) 1999 Annual Meeting 25 (AAEA, 1999).

35. Alves-Pinto, H. N., Hawes, J. E., Newton, P., Feltran-Barbieri, R. \& Peres, C. A. Economic impacts of payments for environmental services on livelihoods of agro-extractivist communities in the Brazilian Amazon. Ecol. Econ. 152, 378-388 (2018).

36. Ragasa, C., Lambrecht, I. \& Kufoalor, D. S. Limitations of contract farming as a pro-poor strategy: the case of maize outgrower schemes in upper West Ghana. World Dev. 102, 30-56 (2018).

37. Maffioli, A., Ubfal, D., Vazquez-Bare, G. \& Cerdan-Infantes, P. Improving technology adoption in agriculture through extension services: evidence from Uruguay. J. Dev. Effect. 5, 64-81 (2013).

38. Green, K. M., DeWan, A., Arias, A. B. \& Hayden, D. Driving adoption of payments for ecosystem services through social marketing, Veracruz, Mexico. Conserv. Evid. 10, 48-52 (2013).

39. Giller, K. E., Witter, E., Corbeels, M. \& Tittonell, P. Conservation agriculture and smallholder farming in Africa: the heretics' view. Field Crops Res. 114, 23-34 (2009).

40. Tricco, A. C. et al. PRISMA extension for scoping reviews (PRISMA-ScR): checklist and explanation. Ann. Intern. Med. 169 , 467-473 (2018)

41. Peters, M. D. J. et al. Guidance for conducting systematic scoping reviews. Int. J. Evid. Based Healthc. 13, 141-146 (2015).

42. Guidelines for Systematic Review and Evidence Synthesis in Environmental Management (Collaboration for Environmental Evidence, 2013); https://go. nature.com/2Hyd0fD

43. Arksey, H. \& O’Malley, L. Scoping studies: towards a methodological framework. Int. J. Soc. Res. Methodol. 8, 19-32 (2005).

44. Levac, D., Colquhoun, H. \& O’Brien, K. K. Scoping studies: advancing the methodology. Implement. Sci. 5, 69 (2010).

45. Piñiero, V. et al. Market, regulatory and compliance incentives for farmers to adopt environmentally sustainable practices: a protocol for a systematic map. Open Science Framework https://osf.io/cmhuq (2019).

46. Covidence Systematic Review Software (Veritas Health Innovation); www.covidence.org

47. Waffenschmidt, S., Knelangen, M., Sieben, W., Bühn, S. \& Pieper, D. Single screening versus conventional double screening for study selection in systematic reviews: a methodological systematic review. BMC Med. Res. Methodol. 19, 132 (2019).

48. Ward, J. H. Jr. Hierarchical grouping to optimize an objective function. J. Am. Stat. Assoc. 58, 236-244 (1963).

49. Demšar, J. et al. Orange: data mining toolbox in python. J. Mach. Learn. Res. 14, 2349-2353 (2013)

50. Barrett, C., Ghezzi-Kopel, K., Hoddinott, J., Tennant, E. \& Upton, J. The state of the literature on individual and household resilience: a scoping review. Open Science Framework https://doi.org/10.17605/osf. io/5rgb7 (2019).

51. What are Market and Non-Market Mechanisms? (United Nations Framework Convention on Climate Change, accessed 10 August 2020); https://go.nature. com/2S7WgxO

\section{Acknowledgements}

We thank C. E. Gonzalez for his contribution to the quantitative analysis of the document corpus and for producing the graphs presented in Figs. 1 and 2. Similarly, we thank D. Amariles for his analysis and presentation of the alluvial diagrams presented in Figs. 2 and 3, and A. M. D. Gonzalez for the data work that is represented in Figs. 4 and 5. We also acknowledge the editing contributions made by M. Eber-Rose. Finally, we thank J. Porciello, whose deep knowledge, drive and understanding made this effort possible. 


\section{Author contributions}

J.R.P. led the search process and contributed to title screening and writing of the methodology section. A.K. contributed to the search process. V.P. liaised with J.R.P. on the search process, coordinated the paper screening, identified the overall research question and contributed to screening at all stages and data extraction, data analysis and writing. J.A., J.D., P.E., A.M.I., C.M.O. and N.O. contributed to screening at all stages, data extraction and writing. S.D.P. contributed to screening at all stages, data extraction, data analysis and writing. M.T. contributed to screening at some stages, data extraction and writing.

\section{Competing interests}

The authors declare no competing interests.

\section{Additional information}

Supplementary information is available for this paper at https://doi.org/10.1038/ s41893-020-00617-y.
Correspondence and requests for materials should be addressed to V.P.

Reprints and permissions information is available at www.nature.com/reprints.

Publisher's note Springer Nature remains neutral with regard to jurisdictional claims in published maps and institutional affiliations.

(c) (i) Open Access This article is licensed under a Creative Commons Attribution 4.0 International License, which permits use, sharing, adaptation, distribution and reproduction in any medium or format, as long as you give appropriate credit to the original author(s) and the source, provide a link to the Creative Commons license, and indicate if changes were made. The images or other third party material in this article are included in the article's Creative Commons license, unless indicated otherwise in a credit line to the material. If material is not included in the article's Creative Commons license and your intended use is not permitted by statutory regulation or exceeds the permitted use, you will need to obtain permission directly from the copyright holder. To view a copy of this license, visit http://creativecommons. org/licenses/by/4.0/.

(C) The Author(s) 2020 